\title{
Homenagem
}

\section{Destruidora de ilusões burguesas: uma homenagem à nossa mãe, Lívia Cotrim}

\author{
Ana Aguiar Cotrim ${ }^{1}$ \\ Vera Aguiar Cotrim²
}

Lívia Cotrim faleceu no último dia 14 de agosto, precocemente, aos 60 anos. Sua despedida foi um acontecimento social, pela presença massiva de pessoas que conviviam ou conviveram com ela em algum momento de sua vida, ultrapassando as dezenas. Não se tratou, contudo, de uma presença impessoal, ao contrário: além de amigos, familiares e colegas, ali se reuniram as três gerações de alunos e ex-alunos que ela formou. Vimos pessoas beirando os 60 e outras ainda adolescentes, carregando a mesma emoção pungente pela perda de sua grande mestra. Muitos fizeram questão de vir nos contar episódios, situações, em que a presença dela foi marcante em suas vidas. Tanto relatos de momentos pontuais de doenças ou perdas, em que ela se fez presente, quanto relatos de grandes processos de mudança de posição na vida: abandono de crenças religiosas, mudanças de caminho profissional e pessoal, rompimento com padrões familiares, libertação feminina e feminista, apreensão de perspectivas revolucionárias, adesão a movimentos sociais e políticos e outros.

Observamos que cada pessoa que estava lá, além de reputar sua formação teórica e ideológica às aulas dela, mantinha com ela uma relação afetiva, em que destacava o cuidado e atenção que receberam. Foi por isso um momento que trouxe para nós, suas filhas, uma clareza muito grande quanto ao significado da sua vida. Nós nascemos quando ela tinha apenas 19 anos, estava na faculdade e já envolvida nas lutas políticas, dedicação que se aprofundou ao longo dos anos. Quando crianças, passávamos todos os fins de semana com nossos avós, enquanto ela estava mergulhada nas atividades intelectuais e de luta, junto com nosso pai. Observávamos o modo como ela tratava seus alunos, alguns dormiam em casa, almoçavam ou jantavam, o cuidado e a amizade que ela lhes dedicava eram patentes. Nós, algumas vezes, tínhamos aquele sentimento infantil de ciúmes ao notar que ela não se importava só conosco.

E era verdade. Numa das últimas conversas que tivemos com ela, ela lia um relato antropológico que tratava do processo da catequização indígena nos Estados Unidos, em que o jesuíta tentava convencer o indígena a assumir a relação monogâmica, argumentando que assim ele

\footnotetext{
1 Doutora, professora da Universidade de Brasília (UnB-FUP). E-mail: anacotrim6@gmail.com.

2 Pós-doutoranda, professora no Cefet-MG. E-mail: veraacotrim@gmail.com.
} 
saberia quem eram os seus filhos. O indígena respondeu que os brancos eram loucos, porque amam apenas seus próprios filhos. E ele queria seguir amando todos os filhos da tribo. Narrou essa história com seus olhos brilhantes, porque, com certeza, se identificava. Ela nunca foi uma mãe da família tradicional. Repugnava-lhe a família tradicional burguesa, mas não a maternidade: foi nossa mãe e de tantos mais: foi uma mãe da tribo.

Essa sua postura seguida durante toda a vida advém da radicalidade com que enfrentou todas as suas relações, pessoais, políticas, intelectuais. Ela é, sem dúvida, a pessoa mais radical que já conhecemos. Essa radicalidade se manifestou também no momento de sua despedida, pela reverberação, falada e escrita, de um modo muito peculiar de descrevê-la: destruidora de ilusões burguesas. Na tentativa de defini-la em uma frase, foi esta a escolhida, espontaneamente, por tantas pessoas que ela formou.

Nada mais adequado para descrever não apenas ao seu modo de viver, mas também a sua produção intelectual. Toda a sua trajetória intelectual pode ser compreendida como um caminho em direção à superação das ilusões burguesas no pensamento e na prática, pautada na perspectiva da emancipação humana, na finalidade da autodeterminação.

A perda das ilusões burguesas, como se sabe, é uma expressão de Marx, quando aborda o primeiro processo histórico que conduziu à identificação dos interesses próprios da classe trabalhadora, em oposição aos interesses da burguesia. Esse processo tem um marco histórico nas Jornadas de Junho de 1848 na França. Nesse momento, em que os trabalhadores foram batidos, mas não abatidos, eles se distinguiram das finalidades de classe da burguesia, definindo-se pela primeira vez como classe oposta à ordem social capitalista. Nisso constitui a sua vitória: a perda de suas ilusões que até então mantinham no republicanismo burguês; e a primeira derrota da burguesia. Nas palavras de Marx, que ela tanto citou:

\footnotetext{
Os trabalhadores parisienses foram esmagados pela superioridade numérica, não foram abatidos por ela. Foram batidos, mas seus opositores foram vencidos. O triunfo momentâneo da força bruta foi comprado com o aniquilamento de todas as mistificações e ilusões da revolução de fevereiro, com a decomposição de todo o velho partido republicano, com a cisão da nação francesa em duas nações, a nação dos proprietários e a nação dos trabalhadores. (NGR, n. 29)
}

Não é causal, portanto, que seja em torno desse processo histórico, as lutas de 1848 na Europa, esse marco, essa raiz da perspectiva de eliminação de todas as classes e toda autoridade, raiz de um novo passo, ainda por ser dado, no caminho da autodeterminação humana, que verse o seu último trabalho. 
Este trabalho consistiu na reunião, tradução do original alemão e apresentação de todos os artigos de Marx e Engels da Nova Gazeta Renana, diário editado por Marx e Engels entre $1^{\circ}$ de junho de 1848 até 19 de maio de 1849. Como ela escreve em sua apresentação, a importância desse material "dificilmente poderá ser sobrestimada, bastando dizer que foi o principal instrumento de ação política de Marx nas revoluções que então se desencadearam". Além de rica fonte histórica, pelo exame das classes e suas relações, das revoluções e contrarrevoluções, é um material central para acessar a concepção de Marx da política e do estado. Esses textos, que compõem cerca de mil páginas, nunca foram traduzidos em seu conjunto para nenhuma língua latina. Existem em português duas pequenas compilações de alguns artigos, a primeira da Editora Ensaio, de que ela participou, a segunda pela Educ, que ela organizou e traduziu. Assim também existem em outras línguas latinas algumas pequenas compilações. O trabalho conjunto, entretanto, é inédito. Em 2010, saiu pela Educ o primeiro volume, a tradução de todos os textos de Marx e aqueles sem autoria, com seu estudo introdutório, edição já esgotada. A tradução do segundo volume, com os textos de Engels, foi finalizada seis meses antes do seu falecimento e o estudo introdutório foi deixado quase pronto.

Este trabalho é parte de um projeto maior, de análise da visão de Marx sobre a política e o estado, que ela intitulou Marx: Política $e$ emancipação humana - 1848-1871, em que ela percorre toda a produção marxiana, centrando no período desde a Nova Gazeta Renana até os textos sobre a Comuna de Paris, e que ainda tampouco foi publicado. Ali, ela desenvolve um dos momentos da revolução teórica marxiana, quer dizer, aquilo que foi sintetizado por José Chasin como as três críticas ontológicas: a crítica da especulação ou idealismo, a crítica da política e do estado (seu caráter intrinsecamente negativo) e a crítica da economia política. É desta revolução que o seu trabalho parte e a qual aprofunda. Toda a sua trajetória intelectual mostra a finalidade de retomar, aprofundar e colocar na ordem do dia esse significado da obra de Marx.

Essa finalidade, contudo, permanece atual. Tanto em termos teóricos como práticos, nos encontramos aquém dessa revolução, como ela sempre enfatizava. Na produção teórica, no universo acadêmico, poucos são os intelectuais e linhas de pensamento que partem dessa revolução, mesmo no campo progressista. Também na atuação prática, as esquerdas no mundo todo, com poucas exceções, abandonaram a perspectiva de superar a forma capitalista e o estado, mesmo como horizonte longínquo. Ao contrário, mostra-se em geral que tanto teórica como praticamente, as representações políticas, sociais e intelectuais da classe trabalhadora recaíram nas ilusões burguesas, capitalistas e republicanas. 
Talvez não seja à toa que os textos da Nova Gazeta Renana tenham sido relegados à “crítica roedora dos ratos", e certamente não é à toa que aquela que foi apelidada por seus estudantes de "destruidora das ilusões burguesas" seja quem realizou a edição latino-americana pioneira do conjunto desses textos de Marx e Engels, em torno do processo em que pela primeira vez uma parcela da humanidade se desprende daquelas ilusões.

Além do eixo de trabalho centrado na dissecação da natureza negativa da política e do estado, as formas do estado republicano e bonapartista, as peculiaridades da revolução política e da revolução social, outros eixos mereceram a sua atenção e estudo. O horizonte do estudo da crítica da política é a ampla questão da autodeterminação humana, que envolve o problema da relação entre indivíduo e gênero. Os eixos de sua pesquisa se vinculam por essa ampla questão.

Assim, ela produziu trabalhos sobre as categorias de individualidade e autodeterminação no renascimento italiano, quer dizer, o período em que precisamente se coloca in statu nascendi a perspectiva prática da autodeterminação humana e princípio da formação da individualidade, examinando Giovanni Pico della Mirandola, Pietro Pomponazzi, Leonardo da Vinci e Giordano Bruno.

A arte, como campo de liberdade e de autoconsciência, também atravessou toda a sua vida como paixão e objeto de estudo. Ela se dedicou ao exame de vários momentos da obra estética de Lukács. A formação do romance, a noção juvenil e madura sobre o cinema - texto que também traduziu pioneiramente para o português - a apropriação lukacsiana das noções estética de Goethe, entre outros temas foram trabalhados por ela. Era conhecedora e amante de toda a obra de Thomas Mann e Balzac, que apresentou também para os estudantes, entre outros artistas e escritores.

Cabe destacar também o seu trabalho nos projetos da Editora Ensaio e Ensaios ad Hominem, durante mais de 20 anos e ao lado da pesquisa e da docência. Esses projetos visavam a publicação, divulgação e estudo, com rigor técnico e intelectual, de obras de Marx e de Lukács, que a "delinquência acadêmica", como referiu um de seus alunos, sempre preferiu legar ao silêncio.

Como parte desses projetos e como pessoa interessada em atuar em seu mundo, ela também de dedicou à análise da realidade brasileira. Participou de um projeto empreendido por José Chasin que buscava compreender a miséria brasileira, termo cunhado a partir da noção marxiana da miséria alemã, ambas focos do estudo e produção da nossa mãe. A sua compreensão da realidade brasileira parte do exame das diferentes formas de entificação do capitalismo no mundo, a via clássica, a 
via prussiana (termo de Lenin para o que Marx denominou a miséria alemã) e a via colonial ou miséria brasileira.

Esse projeto incluiu o exame e crítica conjunta do pensamento conservador brasileiro, para o qual ela realizou a análise dos discursos de Getúlio Vargas. Nesse trabalho, examinou a posição de Vargas quanto ao ordenamento econômico, com ênfase na problemática da autonomia nacional, e quanto à relação com os trabalhadores e a crise que levou ao desfecho de seu governo. Procurou contribuir para a discussão em torno do significado do segundo governo Vargas, especialmente no que diz respeito à temática do "populismo" - criticando assim o modo como a esquerda não marxista entende a realidade brasileira e seus expoentes políticos e teóricos. Examinou a concepção de Chasin sobre a miséria brasileira e sua realidade mais contemporânea, legando-nos um artigo publicado postumamente sobre o golpe de 2016.

Todo esse conjunto de sua produção, a maior parte da qual não se encontra publicada, constitui a herança que nos coube. Mas herdar é uma ação. Apenas a mais tacanha mentalidade burguesa poderia considerar a herança como algo passivo. É preciso, portanto, ser capaz de herdar, de se apropriar efetiva e ativamente da herança. Nós nos sentimos felizes por termos essa condição, que tampouco é casual: fomos formadas por ela. E, novamente, não somos as únicas. Como afirmou Lincoln Secco, em mais de 20 anos como professora de Fundação Santo André, ela apresentou Marx para mais de uma geração de filhos de trabalhadores do ABC, de modo que formou uns tantos herdeiros, muitos dos quais generosamente já se ofereceram para compor essa força de trabalho que significa herdar, e que levaremos adiante: recolher, organizar, publicar e estudar as suas produções.

Se, em meio à nossa tristeza cortante, algo emerge como alegria, é justamente a sua vida, de significado inteiro e radical, de um humanismo fundante e sem igual, e a certeza de sermos a sua ramificação. Se um dia chegarmos à liberdade, ela terá contado com a vida e a atuação de nossa mãe querida, Lívia Cotrim.

Esta homenagem é dedicada a toda a tribo.

Como citar:

COTRIM, Ana; COTRIM, Vera. Destruidora de ilusões burguesas: uma homenagem à nossa mãe, Lívia Cotrim. Verinotio - Revista on-line de Filosofia e Ciências Humanas, Rio das Ostras, v. 25, n. 2, pp. 215-9, nov. 2019.

Data do envio: 10 out. 2019

Data do aceite: 05 nov. 2019 